ANJOS, Gilberto Kilian dos; MOURÃO, Rodrigo Fagundes Mourão. A importância do vínculo associativo para o fortalecimento da magistratura. Revista Eletrônica Direito e Política, Programa de Pós-Graduação Stricto Sensu em Ciência Jurídica da UNIVALI, Itajaí, v.13, n.3, $3^{\circ}$ quadrimestre de 2018. Disponível em: www.univali.br/direitoepolitica - ISSN 1980-7791

\title{
A IMPORTÂNCIA DO VÍNCULO ASSOCIATIVO PARA O FORTALECIMENTO DA MAGISTRATURA
}

\author{
THE IMPORTANCE OF THE ASSOCIATIVE BOND FOR THE STRENGTHENING OF \\ THE JUDICIARY
}

\section{Gilberto Kilian dos Anjos ${ }^{1}$}

Rodrigo Fagundes Mourão²

\begin{abstract}
SUMÁRIO: Introdução; 1 Liberdade de associação; 2 Associativismo na magistratura; 3 Associativismo judicial e democracia; 4 Vínculo associativo dos juízes; Considerações finais; Referências das fontes citadas.
\end{abstract}

\section{RESUMO}

O presente artigo está inserido na linha de pesquisa de direito e democracia e propõe-se a analisar a importância do exercício do vínculo associativo, com foco especial na carreira da magistratura. O trabalho é desenvolvido em quatro tópicos, nos primeiros são abordados aspectos históricos e conceituais dos movimentos associativos e o seu papel na defesa das prerrogativas dos magistrados, em especial da sua independência. No item seguinte, apresenta-se a relação entre associativismo e democracia, demonstrando que o associativismo se reserva dos princípios fundamentais da democracia, em especial os princípios da maioria, da igualdade (material) e da liberdade, formatados para proteção da convivência tolerante e respeitosa das opiniões em divergência. No último subitem, são analisados os obstáculos ao exercício do movimento associativo, decorrentes de contrariedade à decisão tomada pelas maiorias, as frustração e ausência de sintonia entre os agir da associação e os anseios que lhe foram creditados, e o consequente desejo de desvinculação da associação. Na conclusão, o artigo destaca o fato de que em qualquer agrupamento os debates e choques de opiniões são naturais, e que tais circunstâncias não contemplam fundamentação necessária para afastamento das agremiações. Sustenta, ao final, que a força da associação, em última instância, decorre da composição de seu quadro associativo, uma vez que o reduzido quantitativo não reforça a legitimidade, ao contrário, enfraquece a associação, diminuindo o poder de luta pela defesa das prerrogativas e pelos interesses da classe.

Palavras-chave: movimento associativo; magistratura; defesa das prerrogativas; força do vínculo.

1 Juiz de Direito do Estado de Santa Catarina. Pós-graduado em Direito e Gestão Judiciária pelo Centro de Estudos Jurídicos do Tribunal de Justiça de Santa Catarina. Mestrando em Ciências Jurídicas pela Univali, dupla titulação com a Universidade de Alicante, Espanha. E-mail: gilbertokilian@tjsc.jus.br

2 Juiz de Direito do Estado de Santa Catarina. Pós-graduado em Direito e Gestão Judiciária pelo Centro de Estudos Jurídicos do Tribunal de Justiça de Santa Catarina. Mestrando em Ciências Jurídicas pela Univali, dupla titulação com a Universidade de Alicante, Espanha. E-mail: rodrigomourao@tjsc.jus.br 
ANJOS, Gilberto Kilian dos; MOURÃO, Rodrigo Fagundes Mourão. A importância do vínculo associativo para o fortalecimento da magistratura. Revista Eletrônica Direito e Política, Programa de Pós-Graduação Stricto Sensu em Ciência Jurídica da UNIVALI, Itajaí, v.13, n.3, $3^{\circ}$ quadrimestre de 2018. Disponível em: www.univali.br/direitoepolitica - ISSN 1980-7791

\section{ABSTRACT}

This article is part of the line of research on law and democracy and proposes to analyze the importance of exercising the associative bond, with a special focus on the career of the judiciary. The work is developed in four topics, the first deals with historical and conceptual aspects of associative movements and their role in defending the prerogatives of magistrates, especially their independence. In the following item, the relation between association and democracy is presented, showing that associativism reserves the fundamental principles of democracy, especially the principles of majority, (material) equality and freedom, shaped to protect tolerant and respectful coexistence of opinions in divergence. In the last subitem, the obstacles to the exercise of the associative movement are analysed, emerged from the opposition to the decision taken by the majorities, the frustration and lack of harmony between the association's actions and the yearnings that have been credited to it, and the consequent desire of dissociation of the association. In the conclusion, the article emphasizes that in any grouping the debates and shocks of opinion are natural, and that such facts do not contemplate the necessary grounds to leave the associations. In the end, it argues that the strength of the association ultimately derives from the composition of its associative structure, since the small amount of associated does not reinforce legitimacy, but weakens the association, reducing the power to fight for the prerogatives and for the interests of the class.

Keywords: associative movement; magistrature; defense of prerogatives; strength of bond.

\section{INTRODUÇÃO}

A teor da noção inaugural, cuida o texto da dimensão associativa da magistratura, em especial, o ingresso, a permanência e a exclusão do quadro das associações de classe, notadamente, em relação à Associação dos Magistrados Catarinenses - AMC e à Associação dos Magistrados Brasileiros AMB.

De outro lado, aborda o aspecto conceitual e, também, os obstáculos ao exercício do movimento associativo, bem como encaminha reflexão a fim de superar barreiras, com o objetivo de buscar o fortalecimento e a consolidação das associações de classe.

Assim, traçando resumidamente a matéria em foco, o estudo aborda em primeiro plano a liberdade de associação como direito amplo, conferido a todos os cidadãos, em ponto de vista histórico, adentrando no conceito e elementos que o compõe. 
ANJOS, Gilberto Kilian dos; MOURÃO, Rodrigo Fagundes Mourão. A importância do vínculo associativo para o fortalecimento da magistratura. Revista Eletrônica Direito e Política, Programa de Pós-Graduação Stricto Sensu em Ciência Jurídica da UNIVALI, Itajaí, v.13, n.3, $3^{\circ}$ quadrimestre de 2018. Disponível em: www.univali.br/direitoepolitica - ISSN 1980-7791

Após a visão geral do direito de associação, o tópico seguinte discorre acerca do associativismo na magistratura. Isto é, de que modo o direito de associação repercute na carreira da magistratura e, também, os objetivos buscados diante do associativismo na instituição.

No próximo elemento, o trabalho volta a atenção para a relação entre associativismo judicial e democracia. Para tanto, a narrativa contextualiza os princípios fundamentais da ordem democrática e aplicação concreta no âmbito da dimensão associativa da magistratura.

A seguir, o estudo trata do vínculo associativo dos juízes. Ou seja, a motivação para o ingresso, permanência e exclusão, bem como a dinâmica da atuação do associativismo na magistratura.

Por ocasião de encerramento, como conclusão, a demonstrar ponderações acerca dos tópicos abordados, o artigo traz a exposição das considerações finais, resultado dos estudos e reflexões sobre o tema.

O tema, realmente, acalenta opiniões variadas, e é vasto pela sua amplitude. Trata-se de assunto naturalmente espinhoso, cujos diferentes posicionamentos são ancorados com argumentos sólidos e firmes. No entanto, se valer o conteúdo adiante somente pelo debate e união em torno de um propósito comum - o fortalecimento e a consolidação do movimento associativo da magistratura - o trabalho já terá alcançado o escopo pretendido.

\section{LIBERDADE DE ASSOCIAÇÃO}

Em delineamento histórico, SILVA aponta que a liberdade de associação não foi prevista na Declaração dos Direitos do Homem e do Cidadão (1789), bem como se encontra também ausente na Constituição do Império do Brasil ${ }^{3}$. Continua a lecionar que referida liberdade ingressou no direito constitucional pátrio pelo $\S^{\circ}$

3 SILVA, José Afonso da. Curso de direito constitucional positivo. 36. ed. São Paulo: Malheiros, 2013. p. 268. 
ANJOS, Gilberto Kilian dos; MOURÃO, Rodrigo Fagundes Mourão. A importância do vínculo associativo para o fortalecimento da magistratura. Revista Eletrônica Direito e Política, Programa de Pós-Graduação Stricto Sensu em Ciência Jurídica da UNIVALI, Itajaí, v.13, n.3, $3^{\circ}$ quadrimestre de 2018. Disponível em: www.univali.br/direitoepolitica - ISSN 1980-7791

do art. 72 da Constituição de 1891, cujo conteúdo se misturava ao direito de reunião ${ }^{4}$.

Conforme se observa, atualmente a liberdade de associação tem regramento no art. 50, incisos XVII a XX, da Constituição Federal de 1988. Em relação ao conteúdo, lembra TAVARES que a liberdade associação assume o significado: "10) que ninguém poderá ser obrigado a se associar, ou $2^{\circ}$ ) a permanecer associado, ou $3^{\circ}$ ) a abandonar determinada associação, ou $4^{\circ}$ ) autonomia de organização e funcionamento das associações ${ }^{5 "}$.

$\mathrm{Na}$ explicação de TAVARES: "Trata-se de liberdade que, não obstante ser atribuída individualmente a cada cidadão, só poderá ser exercida coletivamente, porque é da essência da associação a existência de duas ou mais pessoas ${ }^{6 \prime \prime}$.

PONTES DE MIRANDA apresenta a associação como "toda coligação voluntária de algumas ou de muitas pessoas físicas, por tempo longo, com o intuito de alcançar algum fim (lícito), sob direção unificante ${ }^{7 \prime}$.

A respeito do direito de associação, SILVA estabelece os seus elementos essenciais, nos seguintes termos: "base contratual, permanência, (ao contrário da reunião), fim lícito (fim não contrário ao direito) ${ }^{81}$. Reitera, também, passagem de ordem primordial a respeito da liberdade de associação, que figura como fundamento para o estudo em tela, pois dentre outros direitos, a liberdade de associação contempla as prerrogativas de "aderir a qualquer associação, pois

4 SILVA, José Afonso da. Curso de direito constitucional positivo. 36. ed. São Paulo: Malheiros, 2013. p. 268.

5 TAVARES, André Ramos. Curso de direito constitucional. 13. ed. São Paulo: Saraiva, 2015. p. 501.

${ }^{6}$ TAVARES, André Ramos. Curso de direito constitucional. 13. ed. São Paulo: Saraiva, 2015. p. 501.

7 PONTES DE MIRANDA apud SILVA, José Afonso da. Curso de direito constitucional positivo. 36. ed. São Paulo: Malheiros, 2013. p. 269.

8 SILVA, José Afonso da. Curso de direito constitucional positivo. 36. ed. São Paulo: Malheiros, 2013. p. 269. 
ANJOS, Gilberto Kilian dos; MOURÃO, Rodrigo Fagundes Mourão. A importância do vínculo associativo para o fortalecimento da magistratura. Revista Eletrônica Direito e Política, Programa de Pós-Graduação Stricto Sensu em Ciência Jurídica da UNIVALI, Itajaí, v.13, n.3, $3^{\circ}$ quadrimestre de 2018. Disponível em: www.univali.br/direitoepolitica - ISSN 1980-7791

ninguém poderá ser obrigado a associar-se; o de desligar-se da associação, porque ninguém poderá compelido a permanecer associado; $(\ldots)^{9 \prime \prime}$.

Direito público subjetivo ${ }^{10}$ na caracterização conceitual expressada por BULOS, como já assinalado, o direito de associação se estende a todas as pessoas físicas, de forma a buscar a união duradora em torno de objetivos lícitos comuns.

Como ressalva SILVA, a salientar o valor tema: "No mais têm as associações o direito de existir, permanecer, desenvolver-se e expandir-se livremente ${ }^{11 "}$.

\section{ASSOCIATIVISMO NA MAGISTRATURA}

A destacar a importância do movimento associativo, já no primeiro parágrafo da obra 'A Política', ARISTÓTELES escreve:

Sabemos que toda cidade é uma espécie de associação, e que toda associação se forma tendo por alvo algum bem; porque o homem só trabalha pelo que ele tem em conta de um bem ${ }^{12}$.

Do ensinamento de FERRAJOLI, extrai-se o arcabouço conceitual para o associativismo:

De fato, o associativismo é um fenômeno coletivo que envolve sempre o desenvolvimento de uma subjetividade coletiva, dotada de identidade própria, sistema de valores próprio, própria razão de ser e, portanto, inevitavelmente, inclinada a lutar em defesa desses valores e princípios programáticos que seguem ${ }^{13}$.

Em comentário ao texto e destaque do pensamento exposto, ressalta-se que o associativismo se caracteriza como fenômeno coletivo, vez que certamente se

9 SILVA, José Afonso da. Curso de direito constitucional positivo. 36. ed. São Paulo: Malheiros, 2013. p. 269. 608.

10 BULOS, Uadi Lammêgo. Curso de direito constitucional. 7. ed. São Paulo: Saraiva, 2012. p.

11 SILVA, José Afonso da. Curso de direito constitucional positivo. 36. ed. São Paulo: Malheiros, 2013. p. 270.

12 ARISTÓTELES. A política. São Paulo: EDIPRO, 1995. p. 11.

13 FERRAJOLI, Luigi. Associazionismo dei magistrati e democratizzazione dell'ordine giudiziario. Questione Giustizia, Roma, n. 4, p. 179, 2015. "Disponível em: <http://www.questionegiustizia.it>. Acesso em: 16 jul. 2017. Tradução livre: "Texto Traduzido". 
ANJOS, Gilberto Kilian dos; MOURÃO, Rodrigo Fagundes Mourão. A importância do vínculo associativo para o fortalecimento da magistratura. Revista Eletrônica Direito e Política, Programa de Pós-Graduação Stricto Sensu em Ciência Jurídica da UNIVALI, Itajaí, v.13, n.3, $3^{\circ}$ quadrimestre de 2018. Disponível em: www.univali.br/direitoepolitica - ISSN 1980-7791

trata de união de esforços, cujo somatório se distingue de cada vontade individual. Ademais, busca o desenvolvimento da coletividade em consideração aos valores que abriga, aliados às diretrizes programáticas almejadas.

Significa dizer que o associativismo não conflui no sentido do magistrado em isolamento, no seu gabinete. Ao contrário, requer participação, se não efetivamente junto aos quadros diretivos, mas ao menos na cobrança dos dirigentes para que sigam os valores albergados e os princípios programáticos estabelecidos pela associação.

Verdade, porém, que IBÁÑEZ aponta visão ampliada do escopo da associação de classe, de sorte a não a limitar apenas no âmbito profissional estrito, abarcando assuntos da política da justiça. É de se transcrever o trecho respectivo:

El ejercicio de ese derecho de asociación es la forma precisa de participación de los jueces en el asunto público de la política de la justicia. Una forma peculiar de participación, como es particular también el estatuto de las propias asociaciones judiciales y el dei mismo juez como ciudadano.

La asociación judicial no es un partido, pero tampoco es un sindicato. En efecto, no se mueve en el ámbito de los sujetos políticos generales; pero tampoco puede circunscribirse a lo reivindicativo-profesional estricto. La difusión del fenómeno associativo genera una nueva forma de relación entre jueces y de éstos con su órgano de gobierno y un modo también nuevo de presencia de los jueces la sociedad ${ }^{14}$.

Muito embora se entenda que a associação de classe possa avançar no âmbito da política da justiça, objetivos mais ampliados, no entanto, não se pode esquecer do seu propósito principal, cujo conteúdo se cinge notadamente nas prerrogativas e condições de trabalho. Com todo o respeito às opiniões contrárias, esse é o núcleo duro do movimento associativo da magistratura e apenas faculta a expansão quando bem solidificado o campo inerente às prerrogativas dos juízes e respectivas condições de trabalho.

14 IBÁÑEZ, Perfecto Andrés. Sobre asociacionismo e independencia judicial. Jueces para la Democracia, n. 25, p. 89, mar. 1996. Disponível em: <http://www.juecesdemocracia.es> Acesso em: 22 ago. 2014. 
ANJOS, Gilberto Kilian dos; MOURÃO, Rodrigo Fagundes Mourão. A importância do vínculo associativo para o fortalecimento da magistratura. Revista Eletrônica Direito e Política, Programa de Pós-Graduação Stricto Sensu em Ciência Jurídica da UNIVALI, Itajaí, v.13, n.3, $3^{\circ}$ quadrimestre de 2018. Disponível em: www.univali.br/direitoepolitica - ISSN 1980-7791

Reverberem-se prerrogativas todas as condições que garantam aos magistrados a possibilidade de julgar com independência, tanto externa, quanto interna. A propósito, independência, cujo significado deveria estar expressamente previsto em nossa Constituição, de igual modo como se visualiza na Constituição Espanhola (art. 117, item 1):

La justicia emana del pueblo y se administra en nombre del Rey por Jueces y Magistrados integrantes del poder judicial, independientes, inamovibles, responsables y sometidos únicamente al imperio de la ley.

Condições de trabalho compreendidas a estruturação funcional, material e, também, a adequada remuneração em consideração às responsabilidades.

E aqui cabe abrir parênteses, ainda que o tema seja tratado de passagem. $O$ movimento associativo da magistratura deve andar desvinculado de outras carreiras. Isso porque, sem falsa modéstia, as responsabilidades e a carga de trabalho são enormes, sem paralelo em confronto a outras carreiras. Então, sendo a magistratura carreira com características únicas, não se vê motivo para espelhamento, principalmente em se tratando do núcleo duro do associativismo, ou seja, prerrogativas e estruturação funcional, material e padrão remuneratório.

Sob outro vértice, salienta-se o direito fundamental dos juízes, a exemplo dos demais cidadãos, de buscar ingressar nas associações de classe e nelas se manterem associados, salvo as de caráter político ou mesmo sindical. A respeito do tema, leciona MIRANDA:

Os juízes, como quaisquer cidadãos, gozam do direito fundamental de associação nas suas diversas vertentes. Podem livremente participar em qualquer associação e constituir entre si associações de diferentes tipos. Com duas exceções: as relativas às associações políticas e aos partidos políticos e às associações sindicais ${ }^{15}$.

Nessa perspectiva, diante da legislação espanhola, IBÁÑEZ defende um associativismo autônomo, sem vínculo formal ou informalmente perante diretrizes político-partidárias, a impedir recaídas ao denominado colaterismo

15 MIRANDA, Jorge. Juízes, liberdade de associação e sindicatos. Themis, Coimbra: Almedina. A. 13, n. $24 / 25$ (2013), p. 14. 
ANJOS, Gilberto Kilian dos; MOURÃO, Rodrigo Fagundes Mourão. A importância do vínculo associativo para o fortalecimento da magistratura. Revista Eletrônica Direito e Política, Programa de Pós-Graduação Stricto Sensu em Ciência Jurídica da UNIVALI, Itajaí, v.13, n.3, $3^{\circ}$ quadrimestre de 2018. Disponível em: www.univali.br/direitoepolitica - ISSN 1980-7791

partidista $^{16}$. De fato, há possibilidade de vinculação ideológica na esfera associativa, como recorda CRISTÓBAL trazendo à luz a situação italiana, cujas associações tem alinhamento com três partidos políticos em consideração à corrente de pensamento: Magistratura indipendente (centro-direita), Magistratura democratica (esquerda) e Unita per la Constituzione (centroesquerda) ${ }^{17}$.

$\mathrm{Na}$ esteira do ensinamento de RAMOS, sublinha-se dispositivo do chamado Estatuto Universal do Juiz, elaborado pela União Internacional de Magistrados, de forma a contemplar o direito de associação, conforme abaixo transcrito ${ }^{18}$ :

O direito de associação profissional do juiz deve ser reconhecido, para permitir aos juízes serem consultados sobre as determinações das normas estatutárias, éticas e outras, aplicação dos recursos orçamentários e para permitir a defesa de seus legítimos interesses.

Reitere-se, assim, que o associativismo no plano judicial, longe de ser observado com reservas, mostra-se digno de todo o apoio. Isso porque, como bem lembra CRISTÓBAL, o associativismo constitui-se, quanto ao aspecto político, patamar inferior em relação à integração sindical ou ao ingresso em partido político ${ }^{19}$. Ou seja, prossegue CRISTÓBAL, o direito de associação se apresenta como vetor que canaliza, a partir de liberdades pessoais, tais quais, de pensamento e expressão, os direitos de cunho político.

Portanto, o direito à associação no âmbito da magistratura se coloca na antessala do sindicalismo e do movimento político-partidário, hipóteses últimas

16 IBÁÑEZ, Perfecto Andrés. Sobre asociacionismo e independencia judicial. Jueces para la Democracia, n. 25, p. 89, mar. 1996. Disponível em: <http://www.juecesdemocracia.es> Acesso em: 22 ago. 2014.

17 CRISTÓBAL, Rosario Serra. El derecho de asociación de los jueces: asociacionismo profesional y asociación del juez a asociaciones no profesionales. Revista Española de Derecho Constitucional, Madrid, v. 28, n. 83, p. 123, mayo/ago. 2008.

18 RAMOS, Jorge. A União Internacional de Magistrados e o Estatuto Universal do Juiz. No Mérito, Rio de Janeiro, n. 50, p. 16-17, ago. 2013. Disponível em: <http://www.amatra1.com.br>. Acesso em: 24 nov. 2018.

19 CRISTÓBAL, Rosario Serra. El derecho de asociación de los jueces: asociacionismo profesional y asociación del juez a asociaciones no profesionales. Revista Española de Derecho Constitucional, Madrid, v. 28, n. 83, p. 118, mayo/ago. 2008. 
ANJOS, Gilberto Kilian dos; MOURÃO, Rodrigo Fagundes Mourão. A importância do vínculo associativo para o fortalecimento da magistratura. Revista Eletrônica Direito e Política, Programa de Pós-Graduação Stricto Sensu em Ciência Jurídica da UNIVALI, Itajaí, v.13, n.3, $3^{\circ}$ quadrimestre de 2018. Disponível em: www.univali.br/direitoepolitica - ISSN 1980-7791

não contempladas ao corpo judicial ${ }^{20}$. Oportunidade ímpar de confluir a manifestação de pensamento e expressão e fazer amplificar na dimensão associativa, de modo a ressoar como expressão de direitos políticos, isto é, na lição de SILVA NETO, a participação do indivíduo na esfera política do Estado²1.

Assim, consideradas as limitações próprias da carreira, em função da imparcialidade e da independência judicial, assume o direito de associação importante destaque para a magistratura na busca de seus objetivos, notadamente pela conjugação e compartilhamento de esforços, de forma duradoura.

Direito de origem fundamental, segundo BULOS florescido no início do século XX, na França ${ }^{22}$, o direito de associação é ferramenta primordial à magistratura a ser valorizado, até porque decorrência da própria conquista e afirmação histórica desta liberdade, de modo que os objetivos sejam primeiramente vistos na lente associativa e não individual. Portanto, aos propósitos associativos, os interesses individuais são considerados à luz da visão associativa, na busca do compartilhamento do consenso e diálogo.

\section{ASSOCIATIVISMO JUDICIAL E DEMOCRACIA}

Como já salientava ZAGREBELSKY no tocante à democracia:

Em qualquer definição de democracia aplicada ao conceito, no entanto, os cidadãos são, no entanto, auxiliados por uma função ativa nas decisões que Ihes dizem respeito. Em todas as outras formas de governo foi ativado; na democracia, devemos ser capazes de ativar. As formas e limites dessa ativação podem ser diferentes, mas essa é a condição sem a qual sobre democracia é impróprio falar ${ }^{23}$.

\footnotetext{
20 CRISTÓBAL, Rosario Serra. El derecho de asociación de los jueces: asociacionismo profesional y asociación del juez a asociaciones no profesionales. Revista Española de Derecho Constitucional, Madrid, v. 28, n. 83, p. 118, mayo/ago. 2008

${ }^{21}$ SILVA NETO, Manoel Jorge e. Curso de direito constitucional. 3. ed. Rio de Janeiro: Lumen Juris, 2008. p. 747.

22 BULOS, Uadi Lammêgo. Curso de direito constitucional. 7. ed. São Paulo: Saraiva, 2012. p. 608.

23 ZAGREBELSKY, Gustavo. La dificile democrazia. Firenze: Firenze University Press, 2010. p. 1. Tradução livre: "Texto traduzido".
} 
ANJOS, Gilberto Kilian dos; MOURÃO, Rodrigo Fagundes Mourão. A importância do vínculo associativo para o fortalecimento da magistratura. Revista Eletrônica Direito e Política, Programa de Pós-Graduação Stricto Sensu em Ciência Jurídica da UNIVALI, Itajaí, v.13, n.3, $3^{\circ}$ quadrimestre de 2018. Disponível em: www.univali.br/direitoepolitica - ISSN 1980-7791

Por outro lado, SILVA aponta que a democracia é um conceito histórico, não se caracterizando por si como valor-fim, todavia ferramenta para concretização de valores primordiais de convivência humana ${ }^{24}$. Aliás, ressalta SILVA que se fala de processo de convivência, a uma para revelar a historicidade, a duas para salientar que afora a relação de poder político, igualmente é modo de vida, cujo relacionamento interpessoal merece a verificação de respeito e tolerância entre os participantes ${ }^{25}$.

Nesse sentir, SILVA prossegue ao lecionar que a doutrina observa que a democracia se fundamenta em três princípios basilares: i) princípio da maioria; ii) princípio da igualdade; iii) princípio da liberdade ${ }^{26}$. Em referência ao associativismo na magistratura, em apreciação aos mencionados princípios, esboçam-se algumas premissas para reflexão acerca do tema em análise.

No que tange ao princípio da maioria, salienta-se o respeito pela deliberação prevalecente, no entanto, sem descurar do direito das opiniões minoritárias, no sentido de não lhes cercear a manifestação de pensamento, isto é, permitir-lhes o espaço apropriado para discussão, a fim de que as chamadas minorias tenham a possibilidade de influência no debate.

Nesse sentido, vale trazer o ensinamento de FERRAJOLI acerca da confrontação referente aos formatos de democracia, a importar significado quanto à intepretação acerca do princípio da maioria. Na primeira visão, o doutrinador a denomina de democracia majoritária ou plebiscitária. Já a segunda concepção, o autor a chama de democracia constitucional ${ }^{27}$.

Continua FERRAJOLI ao afirmar que na primeira acepção, a democracia se apresenta como essencialmente na onipotência da maioria, resultado simplista

24 SILVA, José Afonso da. Curso de direito constitucional positivo. 36. ed. São Paulo: Malheiros, 2013. p. 127-128.

25 SILVA, José Afonso da. Curso de direito constitucional positivo. 36. ed. São Paulo: Malheiros, 2013. p. 128.

26 SILVA, José Afonso da. Curso de direito constitucional positivo. 36. ed. São Paulo: Malheiros, 2013. p. 131.

27 FERRAJOLI, Luigi. Democracia y garantismo. Madrid: Trotta, 2008. p. 25. 
ANJOS, Gilberto Kilian dos; MOURÃO, Rodrigo Fagundes Mourão. A importância do vínculo associativo para o fortalecimento da magistratura. Revista Eletrônica Direito e Política, Programa de Pós-Graduação Stricto Sensu em Ciência Jurídica da UNIVALI, Itajaí, v.13, n.3, $3^{\circ}$ quadrimestre de 2018. Disponível em: www.univali.br/direitoepolitica - ISSN 1980-7791

da soberania popular ${ }^{28}$. Assim, nesse formato, na esteira do ensinamento do doutrinador, além da noção que a maioria legitimaria qualquer abuso, também se constata contrariedade ao sistema de mediações, limites, bem como contrapesos e controles que se estabelecem no que diversamente se poderia chamar de democracia constitucional ${ }^{29}$.

A segunda acepção, conforme FERRAJOLI, aponta a democracia constitucional no conjunto de limitações direcionadas a todo o poder por meio das constituições, garantias e direitos fundamentais e, também, nas técnicas para controlar e reparar violações cometidas $^{30}$.

Logo, pertinente ao princípio em referência, relevante compreendê-lo à luz da democracia constitucional, de modo a rechaçar abusos, impor limites ao poder, tudo em vista a afastar a onipotência da maioria, prejudicial a difusão de ideias e alternância nas esferas de decisão.

Por sua vez, o princípio da igualdade significa que todos, independentemente da posição da carreira, merecem ter igual voz e voto nas decisões associativas. É dizer a igualdade não apenas no caráter formal, mas também no plano substancial.

Além da igualdade de escolha nas diretrizes e propósitos associativos, na fórmula conhecida como one man, one vote ${ }^{31}$, da mesma maneira cabível conceder a oportunidade na defesa das ideias e dos discursos. Nessa ótica, vale registrar o ensinamento de ABREU: "Numa mirada formal, pois, a igualdade exige, a partir de seu reconhecimento, o mesmo tratamento aos iguais. Já sob o prisma material, a igualdade necessita ser construída ${ }^{32 "}$.

\footnotetext{
28 FERRAJOLI, Luigi. Democracia y garantismo. Madrid: Trotta, 2008. p. 25.

${ }^{29}$ FERRAJOLI, Luigi. Democracia y garantismo. Madrid: Trotta, 2008. p. 25.

30 FERRAJOLI, Luigi. Democracia y garantismo. Madrid: Trotta, 2008. p. 27.

31 SILVA, José Afonso da. Curso de direito constitucional positivo. 36. ed. São Paulo: Malheiros, 2013. p. 355.

32 ABREU, Pedro Manoel. O processo jurisdicional como um locus da democracia participativa e da cidadania inclusiva. Florianópolis, 2008. 2 v. Tese (Doutorado) Universidade Federal de Santa Catarina, Centro de Ciências Jurídicas. Programa de Pós-Graduação
} 
ANJOS, Gilberto Kilian dos; MOURÃO, Rodrigo Fagundes Mourão. A importância do vínculo associativo para o fortalecimento da magistratura. Revista Eletrônica Direito e Política, Programa de Pós-Graduação Stricto Sensu em Ciência Jurídica da UNIVALI, Itajaí, v.13, n.3, $3^{\circ}$ quadrimestre de 2018. Disponível em: www.univali.br/direitoepolitica - ISSN 1980-7791

Destarte, mais que igualdade formal a ser reconhecida, porém, igualdade material em permanente construção.

Por fim, relacionado ao princípio da liberdade, confere-se a tolerância e respeito ao posicionamento adotado, de modo a garantir a independência à participação no movimento associativo. Ressalta-se, ademais, a lição de ABREU ao abordar a ampliação da participação democrática, a lembrar o uso da internet para permitir formatação de debate público, isonômico e a custo reduzido, propiciando a todos informação e conhecimento ${ }^{33}$.

Assim, o uso de ferramentas tecnológicas e acesso amplo garantem a liberdade da expressão, de modo a colaborar com a formação da opinião.

Desse modo, o associativismo judicial se reserva dos princípios fundamentais da democracia, vez que formatados para proteção da convivência tolerante e respeitosa das opiniões em divergência, oposições que fazem elevar o diálogo para aprimoramento do interesse geral.

\section{VÍNCULO ASSOCIATIVO DOS JUÍZES}

Com efeito, ao que parece, o adentrar as portas de qualquer movimento associativo deflui das legítimas expectativas, projetos e ideais que the servem de depositário.

A permanência decorre da orientação dos vetores para os mesmos propósitos, bem como a luta para alcançar esses objetivos, não obstante a falta de êxito com fundamento em resultados concretos possa enfraquecer o vínculo perante a associação.

em Direito. Disponível em: <http://www.tede.ufsc.br/teses/PDPC0892-T.pdf> p. 132. Acesso em: 08 dez. 2018.

33 ABREU, Pedro Manoel. O processo jurisdicional como um locus da democracia participativa e da cidadania inclusiva. Florianópolis, 2008. 2 v. Tese (Doutorado) Universidade Federal de Santa Catarina, Centro de Ciências Jurídicas. Programa de Pós-Graduação em Direito. Disponível em: <http://www.tede.ufsc.br/teses/PDPC0892-T.pdf> p. 215. Acesso em: 08 dez. 2018. 
ANJOS, Gilberto Kilian dos; MOURÃO, Rodrigo Fagundes Mourão. A importância do vínculo associativo para o fortalecimento da magistratura. Revista Eletrônica Direito e Política, Programa de Pós-Graduação Stricto Sensu em Ciência Jurídica da UNIVALI, Itajaí, v.13, n.3, $3^{\circ}$ quadrimestre de 2018. Disponível em: www.univali.br/direitoepolitica - ISSN 1980-7791

$\mathrm{Na}$ desconfiança, frustração e ausência de sintonia entre o agir associativo e os anseios que the foram creditados surge o desejo de desvinculação da associação.

Se for certo que 0 ingresso se fia na possibilidade e a exclusão funda-se na quebra de perspectiva, não menos correto que a permanência resulta da viabilidade do projeto.

Nessa linha de pensamento, crível que o rumo associativo se faça numa escala global, cujo conteúdo contemple várias propostas, vetores que alcancem uma virtual sinergia aos anseios da classe.

Igualmente, em continuidade, não menos plausível - fator comum a qualquer agrupamento - que alguns apontamentos não sejam consenso, isto é, causem estranhamento, controvérsia e áspero debate.

Entretanto, a despeito de choque de opiniões, a menos que se tenha absoluta colidência com a planificação de intenções e ações da associação, não se contempla fundamentação necessária para o afastamento da agremiação.

Isso porque, afora o confronto absoluto de ideias e opiniões - razão a justificar a tomada pelo afastamento - o foro para discuti-las se faz imerso no âmago da associação, não fora.

Noutras palavras, significa dizer que a contrariedade à decisão - mesmo que tomada pela associação de maneira não democrática - implica a insurgência dentro da agremiação, de modo a ampliar o conteúdo argumentativo, a esfera de discussão, ao passo que a dissolução do vínculo apenas tangencia o problema, isto é, não ataca o fundamento primário.

Sob outro prisma, cabível destacar que a força da associação, em última instância, decorre da composição do quadro associativo. O reduzido quantitativo não reforça a legitimidade, ao contrário, enfraquece a associação, diminuindo o poder de luta pela defesa das prerrogativas e pelos interesses da classe.

Em tempos de nítido conflito e embate dos mais variados grupos, parece correto o caminho de fortalecimento associativo, até porque a desintegração associativa 
ANJOS, Gilberto Kilian dos; MOURÃO, Rodrigo Fagundes Mourão. A importância do vínculo associativo para o fortalecimento da magistratura. Revista Eletrônica Direito e Política, Programa de Pós-Graduação Stricto Sensu em Ciência Jurídica da UNIVALI, Itajaí, v.13, n.3, $3^{\circ}$ quadrimestre de 2018. Disponível em: www.univali.br/direitoepolitica - ISSN 1980-7791

não extinguirá o vínculo de origem da união, ou seja, a condição de estar na carreira da magistratura.

Importante salientar, nesse aspecto, que em tempos de reiterados ataques ao Poder Judiciário, bem como à figura central que o compõe - o juiz -, a associação se faz valer como verdadeiro escudo de proteção, na finalidade de rechaçar agressões e, também, à busca da consolidação das garantias constitucionais ao exercício profissional e de aproximação da magistratura com a sociedade civil.

Em verdade, o cargo de magistrado faz surgir o liame institucional, cuja expansão resulta o caráter associativo. No entanto, os propósitos institucional e associativo não se confundem, por vezes são até divergentes. A defesa da classe, em certos casos, é refratária ao interesse estatal.

Por fim, cabe salientar que é livre o direito à integração no movimento associativo. De igual forma, princípio democrático a liberdade de não participar. É questão puramente de escolha. Porém, recorda-se que constitucionalmente é vedado ao magistrado dedicar-se à atividade político-partidária. Em análise singela, a cumprir a vedação imposta, percebe-se a dificuldade do magistrado singularmente reivindicar pleito que diga respeito à atividade desempenhada, ao cargo ocupado e à carreira percorrida, principalmente quanto às esferas dos Poderes Legislativo e Executivo. Não se observa o caminho adequado, senão por intermédio da associação. Repita-se que o interesse estatal nem sempre é coincidente com o associativo.

\section{CONSIDERAÇÕES FINAIS}

Ao término da exposição, em síntese dos fundamentos tratados, cabem as considerações finais:

(i) o direito de associação é público subjetivo contemplado a todos os cidadãos, a merecer valorização na magistratura como decorrência da conquista histórica dessa liberdade; 
ANJOS, Gilberto Kilian dos; MOURÃO, Rodrigo Fagundes Mourão. A importância do vínculo associativo para o fortalecimento da magistratura. Revista Eletrônica Direito e Política, Programa de Pós-Graduação Stricto Sensu em Ciência Jurídica da UNIVALI, Itajaí, v.13, n.3, $3^{\circ}$ quadrimestre de 2018. Disponível em: www.univali.br/direitoepolitica - ISSN 1980-7791

(ii) o associativismo se vincula à democracia, notadamente em relação aos princípios da maioria, igualdade e liberdade;

(iii) o movimento associativo resulta da disposição dos indivíduos em volta a interesse comum;

(iv) o ingresso na associação se relaciona com as legítimas expectativas, projetos e ideais que Ihe são confiados;

(v) a permanência no movimento associativo manifesta-se no direcionamento para os propósitos almejados, bem como a luta para alcançá-los, muito embora a não obtenção de resultados concretos possa debilitar a ligação associativa;

(vi) o afastamento da associação decorre da desconfiança, frustação e ausência de sintonia entre o agir associativo e anseios creditados à associação;

(vii) fator comum a qualquer agrupamento é que a pauta de propostas não seja consenso e, em consequência, acarrete estranhamento, controvérsia e áspero debate;

(viii) apesar do confronto de opiniões, a menos que haja absoluto conflito com o plano de intenções e ações da associação, não se contempla motivação suficiente para o afastamento do associado, porquanto o espaço adequado para a discussão de ideias é no âmago da associação, a valer a ampliação do conteúdo argumentativo, ao passo que a dissolução do vínculo associativo apenas tangencia o problema e não questiona a causa primária;

(ix) a força associativa resulta do quadro da associação, sendo que a diminuta quantia de associados não reforça a legitimidade e debilita o movimento associativo;

( $x$ ) em época de intensa controvérsia e disputa entre os mais diversos grupos, coerente o fortalecimento associativo, mesmo porque a desintegração associativa não dissolverá o vínculo de origem, qual seja, o cargo de magistrado; 
ANJOS, Gilberto Kilian dos; MOURÃO, Rodrigo Fagundes Mourão. A importância do vínculo associativo para o fortalecimento da magistratura. Revista Eletrônica Direito e Política, Programa de Pós-Graduação Stricto Sensu em Ciência Jurídica da UNIVALI, Itajaí, v.13, n.3, $3^{\circ}$ quadrimestre de 2018. Disponível em: www.univali.br/direitoepolitica - ISSN 1980-7791

(xi) o cargo de magistrado faz surgir o vínculo institucional que, em expansão, decorre o caráter associativo, elementos não assemelhados e, por vezes, até divergentes;

(xii) em decorrência da vedação constitucional de se dedicar à atividade políticopartidária, constata-se a dificuldade do juiz singularmente reivindicar pleitos relacionados à atividade, ao cargo e à carreira, em especial, frente aos demais Poderes, razão pela qual o movimento associativo busca atuar nessa tarefa.

\section{REFERÊNCIA DAS FONTES CITADAS}

ABREU, Pedro Manoel. O processo jurisdicional como um locus da democracia participativa e da cidadania inclusiva. Florianópolis, 2008. 2 v. Tese (Doutorado) - Universidade Federal de Santa Catarina, Centro de Ciências Jurídicas. Programa de Pós-Graduação em Direito. Disponível em: <http://www.tede.ufsc.br/teses/PDPC0892-T.pdf> Acesso em: 08 dez. 2018.

ARISTÓTELES. A política. São Paulo: EDIPRO, 1995.

BULOS, Uadi Lammêgo. Curso de direito constitucional. 7. ed. São Paulo: Saraiva, 2012.

CRISTÓBAL, Rosario Serra. El derecho de asociación de los jueces: asociacionismo profesional y asociación del juez a asociaciones no profesionales. Revista Española de Derecho Constitucional, Madrid, v. 28, n. 83, p. 115145, mayo/ago. 2008.

FERRAJOLI, Luigi. Democracia y garantismo. Madrid: Trotta, 2008.

Associazionismo dei magistrati e democratizzazione dell'ordine giudiziario. Questione Giustizia, Roma, n. 4, p. 178-184, 2015. Disponível em: <http://www.questionegiustizia.it>. Acesso em: 16 jul. 2017. Tradução livre: "Texto traduzido".

IBÁÑEZ, Perfecto Andrés. Sobre asociacionismo e independencia judicial. Jueces para la Democracia, n. 25, p. 88-93, mar. 1996. Disponível em: <http://www.juecesdemocracia.es> Acesso em: 22 ago. 2014.

MIRANDA, Jorge. Juízes, liberdade de associação e sindicatos. Themis, Coimbra: Almedina. - A. 13, n. 24/25 (2013), p. 7-24.

SILVA, José Afonso da. Curso de direito constitucional positivo. 36. ed. São Paulo: Malheiros, 2013. 
ANJOS, Gilberto Kilian dos; MOURÃO, Rodrigo Fagundes Mourão. A importância do vínculo associativo para o fortalecimento da magistratura. Revista Eletrônica Direito e Política, Programa de Pós-Graduação Stricto Sensu em Ciência Jurídica da UNIVALI, Itajaí, v.13, n.3, $3^{\circ}$ quadrimestre de 2018. Disponível em: www.univali.br/direitoepolitica - ISSN 1980-7791

SILVA NETO, Manoel Jorge e. Curso de direito constitucional. 3. ed. Rio de Janeiro: Lumen Juris, 2008.

RAMOS, Jorge. A União Internacional de Magistrados e o Estatuto Universal do Juiz. No Mérito, Rio de Janeiro, n. 50, p. 16-17, ago. 2013. Disponível em: <http://www.amatra1.com.br>. Acesso em: 24 nov. 2018.

TAVARES, André Ramos. Curso de direito constitucional. 13. ed. São Paulo: Saraiva, 2015.

VIANNA, Luiz Werneck; et al. Corpo e alma da magistratura brasileira. 3. ed. Rio de Janeiro: Revan, 1997.

ZAGREBELSKY, Gustavo. La dificile democrazia. Firenze: Firenze University Press, 2010. 30 p. Tradução livre: "Texto traduzido".

Recebido em: 02/12/2018

Aprovado em: 14/12/2018 